\title{
A Dual Approach to Model Some Basic Equations in Fluid Mechanics
}

\section{The-Hung Nguyen*}

Faculty of Water Resources Engineering, University of Science and Technology, The University of Danang, Vietnam

*Corresponding Author: The-Hung Nguyen, Faculty of Water Resources Engineering, University of Science and Technology, The University of Danang, Vietnam.
Received: May 25, 2021

Published: May 27, 2021

(C) All rights are reserved by The-Hung

Nguyen.

Keywords: Dual Approach; Classic Average Method; Two-dimensional Horizontal Flow Equation; Two-dimensional Vertical Flow Equation; Two-dimensional Horizontal Solute Transport Equation; Two-dimensional Vertical Solute Transport Equation.

In current, the basic equations in fluid flow or solute transport as one-dimensional (1D), two-dimensional horizontal (2DH), twodimensional vertical (2DV), three-dimensional (3D) flow were established by the classic average method, do not generalize by means of dual approach [1,2,4-7]. Therefore, in this paper, a dual approach is applied to construct some basic equations (1D, 2DH, 2DV) in fluid flow and solute transport [4-7].

\section{For the 2DH flow}

In the classic average method, the $2 \mathrm{DH}$ flow model is integrated from 3D Reynolds averaged Navier-Stokes Equations system. With the classical theory, the integral approach is taken from the bed to the free water surfaces. According to this dual-process approach, the setup model will be more complex than the classical approach; the integral can be performed locally several times, the 2DH flow performed by integrating twice; the receiving equations allow to contain many physical phenomena which may be lost or inaccurate in the classic average method $[1,2,5,8]$.

\section{For the 2DV flow}

The mathematical model of 2DV flow, in currently, is constructed by the classic average method which is integrated from the right to the left river bank of the 3D Reynolds averaged Navier-Stokes equations; the average quantities received by this approach do not generalize by means of dual approach $[1,2,7,8]$. In this study, a dual approach is applied to establish the 2DV flow equations; the setup model will be more complex than the classical approach, the integral can be performed locally several times. In this study, the 2DV performed by integrating twice: the first, integration from the right river bank to the intermediate vertical surface layer between the right bank and the left bank; and then the second, integration from the right bank to the left bank [7].
The improved two-dimensional vertical flow model was received from this dual approach allows the calculation of flow parameters more accurate than the classical average method. In other words, it provides some flexible parameters to adjust based on the field or experimental data $[7,8]$.

\section{For the 1D flow}

From the 2DH and 2DV flow model established by dual approach, we received the $1 \mathrm{D}$ flow model $[5,7,8]$.

\section{For the solute transport equation of 2DH flow}

In the classical method, the $2 \mathrm{DH}$ solute transport equation is totally integrated one time from the bed to the water surface; the average values received by classic average method do not generalize by means of dual approach. In this study, the dual approach is applied to receive the solute transport equation of 2DH flow. The equation describing the depth average concentration is obtained by integrating twice: the first time, integral is from the bed to the intermediate surface lays between bed to free water surface, the second time, integral is from the bed to the free water surface. With the dual approach, the received depth average concentration is better, particularly, in the case of stratification, mixed solute, and so on $[1,2,4,8]$.

\section{For the solute transport equation of $2 \mathrm{DV}$ flow}

The solute transport equation of $1 \mathrm{D}$ or 2DV flow is normally constructed by the classic average method. These solute transport equations are integrated from the right to the left river bank; the average values received by this approach therefore do not generalize by means of dual approach. This paper presents the application of a dual approach to establish the 2DV solute transport equation. 
In particular, the concentration in a 2DV flow is obtained by integrating twice: the first, integration from the right river bank to the intermediate vertical surface layer between the right bank and the left bank, and then the second, integration from the right bank to the left bank. The average concentration obtained from the dual approach is better than the classical approach, particularly, in the case of mixed solute transport, stratification, and etc. A case study of solute transport (salinity transport) in Huong river system was illustrated $[1,2,6,8]$.

For the solute transport equation of 1D flow

From the 2DH [4] and 2DV [6] solute transport model was established by dual approach, we received 1D solute transport model $[4,6,8]$.

\section{Bibliography}

1. Nguyen Dong Anh. "Dual approach to averaged values of functions". Vietnam Journal of Mechanics, VAST 34.3 (2012): 211214.

2. Nguyen Dong Anh. "Dual approach to averaged values of functions: Advanced formulas". Vietnam Journal of Mechanics, VAST 34.4 (2012): 321-325.

3. NGUYEN The Hung. "Salinity intrusion in Huong river network and the measure of hydraulic construction". The Journal of Science and Technology (Five University of Technology) 2 (1992): $17-21$.

4. Hung NGUYEN The. "A dual approach to modeling solute transport". The International Conference on Advances in Computational Mechanics (2017): 821-834.

5. Tinh Ton That., et al. "A dual approach for model construction of two-dimensional horizontal flow". Proceedings of the 10th International Conference on Asian and Pacific Coasts (APAC 2019) Hanoi, Vietnam, Sept. 25-28 (2019): 115-120.

6. Hung NGUYEN The. "A dual approach for modeling two- and one-dimensional solute transport". The International Conference on modern mechanics and applications (2020).

7. Hung NGUYEN The. "Mathematical model of two-dimensional vertical flow by dual approach". The National Conference on Fluid Mechanics (2021).

8. Weiming Wu. "Computation river dynamics". Taylor and francis/Balkema (2007).
Volume 5 Issue 6 June 2021

(c) All rights are reserved by The-Hung Nguyen. 